\title{
A Folding Method to Increase the Rigidity of Paperboard Tray Packages
}

\begin{abstract}
Arvo Niini,* Panu Tanninen, Teija Laukala, Juha Varis, and Ville Leminen
The flange of press-formed paperboard trays was reshaped in this work with a developed folding method to increase the rigidity of the trays. The tray rigidity was evaluated with compression, torsion, and storing tests. The rigidity of the folded trays and the reference trays was compared, and the quality of the trays was investigated with an optical analysis. The folding temperature was altered to 23,60 , and $90^{\circ} \mathrm{C}$ to compare the effects of heat input on the tray rigidity. The compression and torsion test results linked the increased tray rigidity to the additional heat input and surface pressure induced to the material in the folding phase. The trays that were folded at $90{ }^{\circ} \mathrm{C}$ showed a $43 \%$ higher compression force and a $12 \%$ smaller torsion angle compared to the reference trays. The storing tests showed an unclear effect on the tray rigidity to the dimensional stability, and the optical analysis depicted similar quality between the folded and the reference trays. The folding method was found to enhance the stacking and end use capabilities of paperboard tray packages, and the use of higher folding temperatures was suggested to increase the strength and stiffness of the trays.
\end{abstract}

DOI: 10.15376/biores.17.1.1427-1441

Keywords: Press-forming; Surface topography; Compression strength; Torsional stiffness; Dimensional stability

Contact information: Department of Mechanical Engineering, Lappeenranta-Lahti University of Technology LUT, Yliopistonkatu 34, 53850 Lappeenranta, Finland;

* Corresponding author: Arvo.Niini@lut.fi

\section{INTRODUCTION}

Tray packages can be found from many food container applications in the modern packaging industry. Paperboard trays can be manufactured with press-forming. The stiffness and strength of the press-formed trays are important in determining their usability. Increased tool temperature in the press-forming was previously found to improve the compression strength of paperboard trays (Leminen et al. 2020). Increased forming force and blank holder force were also connected to the improved rigidity of paperboard trays (Leminen et al. 2018).

Humidity exposure can lead to stiffness degradation and dimensional instability of paperboard, limiting the use of paperboard trays in moist environments typical to the production and storing of food packages. The drying and heat-sealing of paperboard trays improved the dimensional stability in a previous work (Niini et al. 2021), yet the negative humidity effect to the tray rigidity was not eliminated. The humidity exposure yields creep deformation in tray packages, and cyclic humidity conditions aggravate the creep (Sørensen and Hoffmann 2004). Wang and Sun (2018) linked the stiffness degradation of paperboard to a fatigue failure, and the bending stiffness of paperboard under a cyclic 
loading was connected to the resistance of paperboard fibers against gradual plastic deformation.

The importance of fiber bonding in the three-dimensional (3D) forming of paperboard structures was studied by Hauptmann et al. (2015). Bonding of the material fibers in the forming process contributed to tensile strength and bending stiffness of the paperboard structures. Wrinkling of paperboard from the deformation of the fiber network could be adjusted with the blank holder force (Hauptmann et al. 2015). Preventing wrinkling of paperboard by adapting blank holder force trajectory was consequently found to improve the visual quality of formed paperboard structures in another study by Hauptmann et al. (2016).

The influence of moisture content on the forming behavior of paperboard was investigated by Stein et al. (2019). Their investigation associated the moisture content of paperboard with the material forming limits and the stiffness of the formed structures. Based on the findings of Hofmann et al. (2019), increased moisture content weakens the fiber network of paperboard in the forming process and the weakened fiber network yields lower breaking strength and improved formability. The increased moisture content in the paperboard packages in turn weakens the fatigue resistance of the packages, as observed by Lamb and Rouillard (2017). The static compression strength of paperboard food packages decreased exponentially when the package moisture content was increased in a study by Sørensen and Hoffmannn (2003). As a result, the moisture content has an important role in both the manufacturing and use of paperboard packages.

Modifying the geometry of paperboard packages can yield varying effects to the rigidity and usability of the packages. Increasing the vent area of paperboard packages was found to improve the cooling efficiency of the packages whilst reducing the compression strength (Berry et al. 2017). Larger vent area holes in paperboard packages were found to have a negatively linear relationship with the compression strength by Fadiji et al. (2019). Hoffmann (2000) associated larger edge rounding with the increased compression strength of molded pulp packages. The recent studies about the modification of package geometry have focused on improving the conditioning of the package content. Modifying the geometry of tray packages to improve the strength and stiffness has not been studied before. Moreover, the rigidity and quality of paperboard tray packages is connected to the shaping of the tray flange and bottom during the 3D forming process (Tanninen et al. 2018). Achieving and sustaining a sufficient rigidity with the paperboard trays is especially important in the demanding environment of food packaging applications (Niini et al. 2021).

This work utilized a folding method to increase the rigidity of paperboard tray packages. The flange of the trays was reshaped with an experimental folding device. The scope of the study included the development of the folding device and testing of its effects to the tray rigidity. The rigidity of the trays was evaluated with compression, torsion, and storing tests. The quality of the trays was inspected with an optical analysis of the surface topography of the tray flange. The main innovation of the folding method was to improve the rigidity of paperboard tray packages to enhance their stacking, storing, and end use capabilities. 


\section{EXPERIMENTAL}

\section{Materials}

The tested trays were manufactured using a commercial three-ply paperboard with a polyethylene terephthalate (PET) coating. The material contained a chemithermomechanical pulp (CTMP) middle layer and solid bleached sulfate (SBS) outer layers. The indicated grammage was $350 \mathrm{~g} / \mathrm{m}^{2}$ for the substrate and $40 \mathrm{~g} / \mathrm{m}^{2}$ for the coating. The material thickness was $480 \mu \mathrm{m}$. The material was stored in a humidity chamber at $80 \%$ relative humidity $(\mathrm{RH})$ before the tray blanks were die-cut. The tray blanks were similarly stored at $80 \% \mathrm{RH}$ before press-forming of the trays. The moisture content of the tray blanks and the press-formed trays was measured with an Adams Equipment PMB 53 moisture analyzer (Oxford, CT, USA). The obtained moisture contents were $9.8 \%$ for the tray blanks and $6.3 \%$ for the press-formed trays.

\section{Methods}

The studied tray geometry was GN 1/4 with the reference dimensions of $265 \mathrm{~mm} \times$ $162 \mathrm{~mm} \times 38 \mathrm{~mm}$, in accordance with the SFS-EN standard 631-1 (2013). The experimented folding method was designed for the GN 1/4 tray, for which press-forming tools (Fig. 1) were available. The trays were manufactured using a die-cutter and a packer of the LUT Packaging Line (Lappeenranta, Finland). The tray blanks were die-cut with the machine direction (MD) of the material parallel to the longer side of the tray.

The press-forming of the trays was done with a $150{ }^{\circ} \mathrm{C}$ female mold tool temperature, a $0.96-\mathrm{kN}$ blank holding force, a $150-\mathrm{kN}$ pressing force, a $1 \mathrm{~s}$ dwell time, and an $80-\mathrm{mm} / \mathrm{s}$ pressing speed. A detailed description of the press-forming process was outlined in the previous work by Leminen et al. (2020).

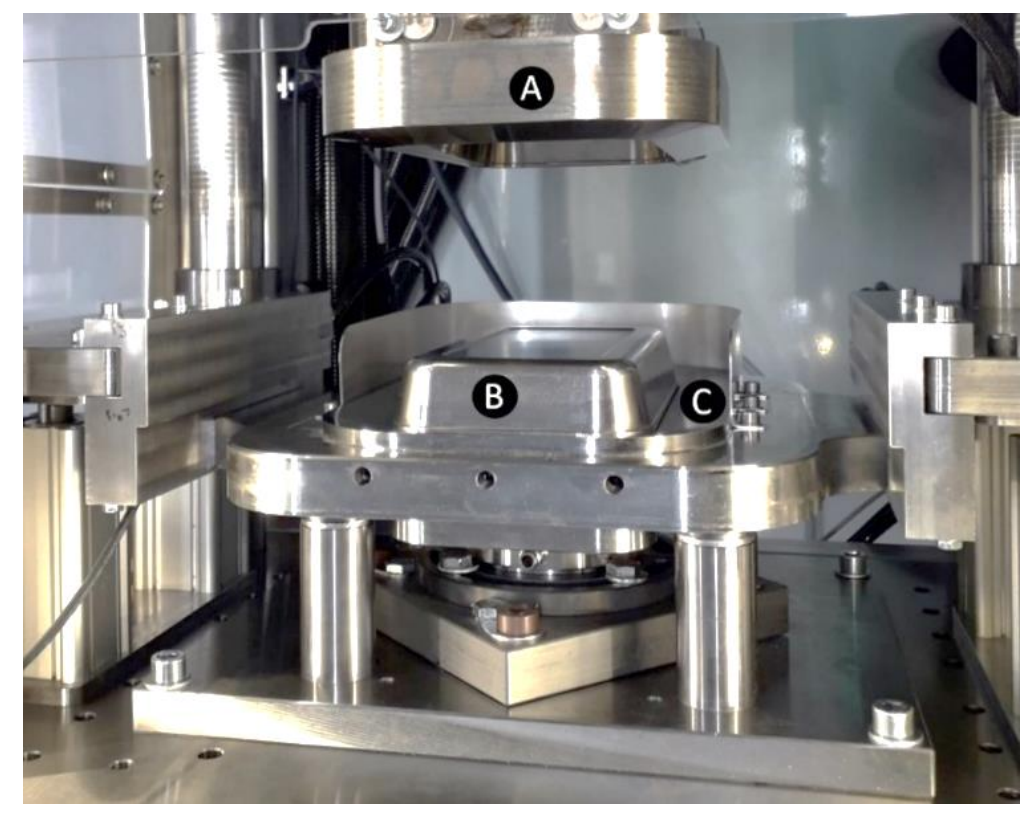

Fig. 1. (a) Female mold, b) male mold, and c) blank holder of the GN $1 / 4$ press-forming tool set

An experimental folding device (Fig. 2) was developed to reshape the flange of the press-formed trays. The tray (A) was placed on a support ring (B), around which a fold was formed. The rigidity of the lower part of the tool was ensured by platform plates (C). The 
amount of the plates was adjusted according to the tray height. The upper part of the device included counter plates (D). The counter plates formed the outer edge of the fold and flattened the tray flange to its final shape. The tool temperature could be adjusted with a heating unit $(\mathrm{E})$. The support ring aligned the tray with a base plate $(\mathrm{F})$.

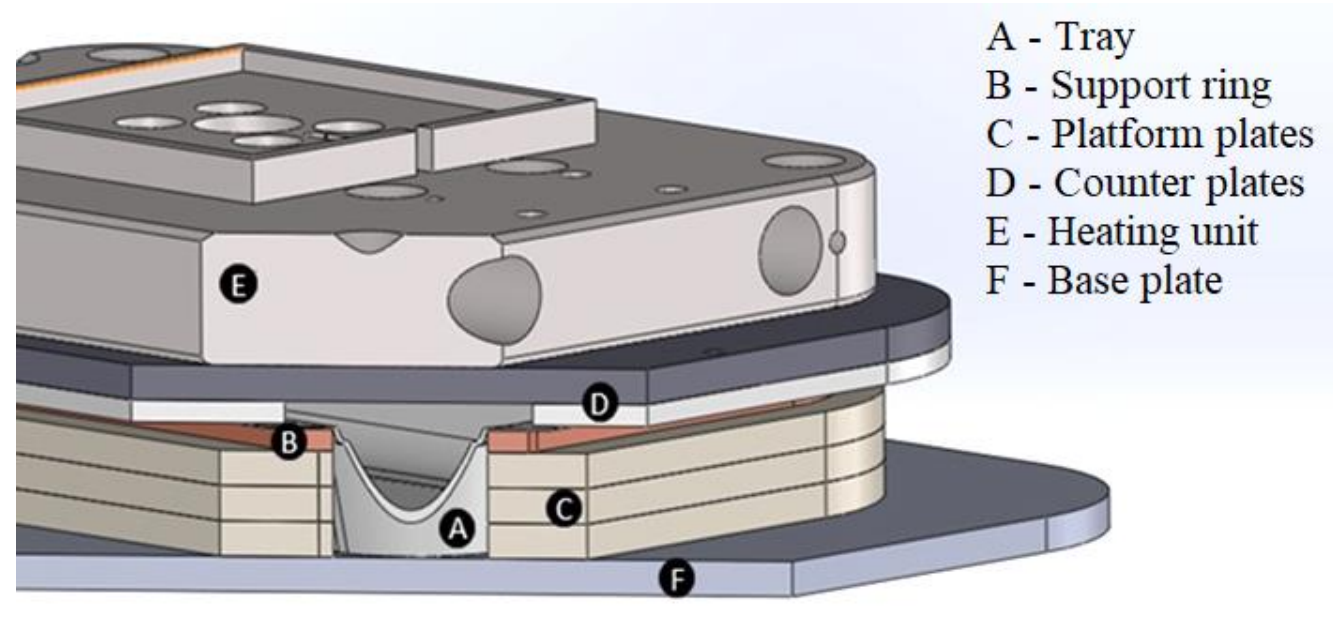

Fig. 2. A tray flange folding device. The cutaway view shows a paperboard tray inserted to the device at the beginning of the flange reshaping process.

The folding method was investigated with the specific device in this study, though the flange reshaping phase was designed to be integrated with the used GN 1/4 pressforming tool set to maintain the production speed. The reshaping was confined to the tray flange (Fig. 3) to preserve the functionality of the trays.

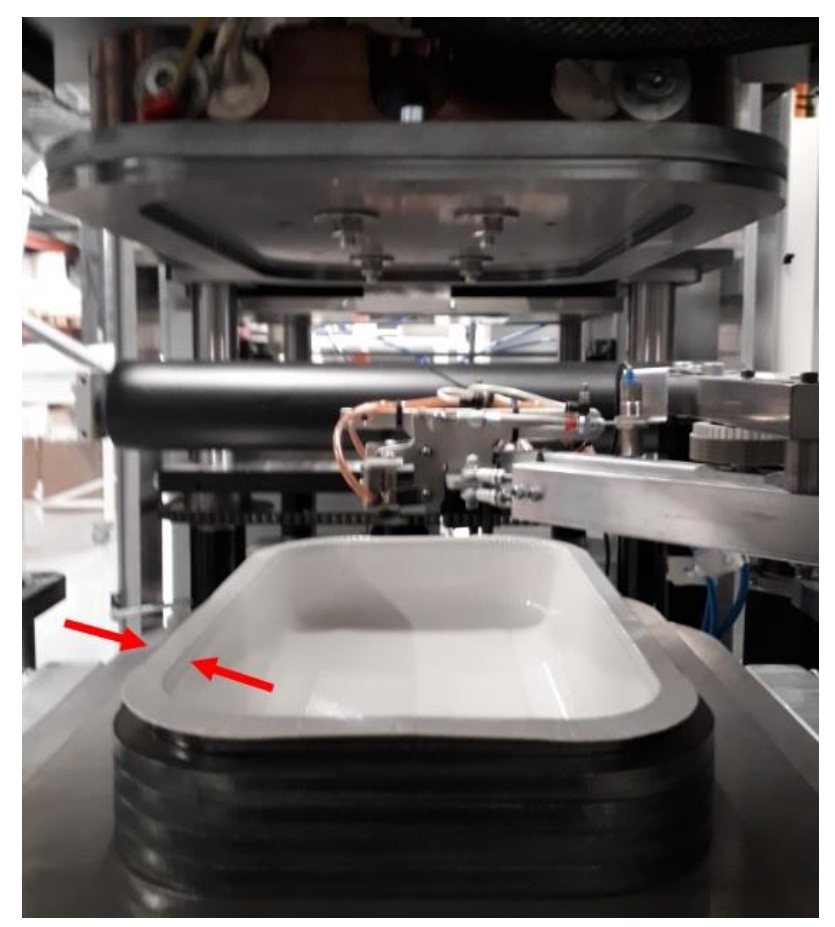

Fig. 3. Tray inserted to the folding device before folding of the tray flange. The flange region is highlighted with red arrows, 
The folding of the trays was done with the maximum parameters (Table 1) of the folding device. The tool temperature was altered to investigate the effects of increased folding temperature to the rigidity of the folded trays. The maximum tool temperature was kept at $90{ }^{\circ} \mathrm{C}$ to avoid damaging the PET coating.

Table 1. Folding Parameters

\begin{tabular}{|c|c|c|c|}
\hline Tool Temperature & $23^{\circ} \mathrm{C}$ & $60^{\circ} \mathrm{C}$ & $90^{\circ} \mathrm{C}$ \\
\hline Dwell Time & \multicolumn{3}{|c|}{$\mathrm{s}$} \\
\hline Pressing Speed & \multicolumn{3}{|c|}{$30 \mathrm{~mm} / \mathrm{s}$} \\
\hline Pressing Force & \multicolumn{3}{|c|}{$75 \mathrm{kN}$} \\
\hline
\end{tabular}

An optical analysis was conducted on the surface topography of the PET coating near the fold of the tray flange to inspect the visual quality of the folded trays. The surface topography was observed with a Hitachi SU3500 scanning electron microscope (SEM) (Tokyo, Japan). The samples for the optical analysis were cut from the longer side of the tray flange. The graphing of the samples with the SEM was done using a tungsten filament and a secondary electron (SE) detector, and the samples were $\mathrm{Au} / \mathrm{Pd}$ target sputter-coated before the graphing. The utilized acceleration voltage was $200 \mathrm{~V}$, and the working distance was adjusted to 14.5 to $15.5 \mathrm{~mm}$ with the samples.

The rigidity of the folded trays was studied with compression, torsion, and storing tests. The trays were heat-sealed with a lidding film for the compression and storing tests with an Ilpra speedy tray sealer (Mortara, Italy) using a $210{ }^{\circ} \mathrm{C}$ sealing temperature, a 2.5 $\mathrm{s}$ sealing time, and a 6-bar sealing pressure. A flat metal bar with a weight of $0.4 \mathrm{~kg}$ was packed to the trays before the heat-sealing. The packing and the sealing of the trays represented the typical processing of food containers. A lidding film (Ambar $F$ 310/838BA5 TS; AMB Packaging, Udine, Italy) with a thickness of $83 \mu \mathrm{m}$ was used to seal the trays.

The compression tests (Fig. 4) were done with a Shimadzu AGS-10kNX universal tester (Kyoto, Japan) using a 100-mm/min compression speed. The displacement in the compression tests was adjusted to $12 \mathrm{~mm}$ to observe the initial compression of the tray flange region. The trays were heat-sealed and loaded with the $0.4 \mathrm{~kg}$ weight for the compression tests to simulate the stacking of packed food containers.

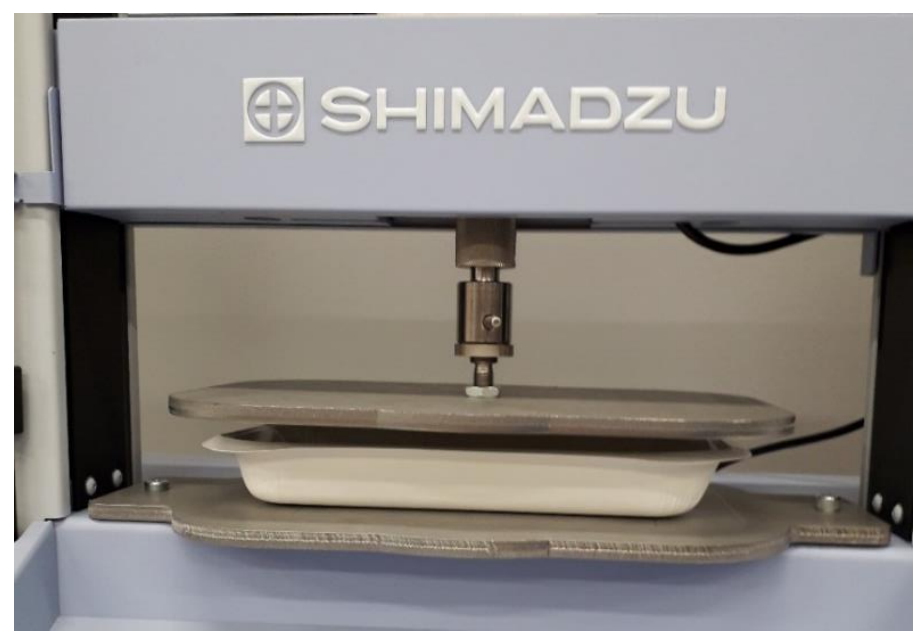

Fig. 4. Tray compression test 
The torsion tests were done using an LUT tray stiffness tester (Lappeenranta, Finland). An empty tray was clamped to the stiffness tester from its shorter sides. The trays were clamped with one fixed holding clamp and one rotating holding clamp to enable their twisting (Fig. 5). The theoretical area moment of inertia was calculated as $253.2 \mathrm{~kg} \cdot \mathrm{m}^{2}$ for the used axis of rotation and tray geometry, and the moment of inertia was interpreted to represent the torsion constant. The shorter side of the trays was twisted clockwise and then counterclockwise with a $120 \mathrm{~g}$ weight that corresponded to a $0.036 \mathrm{Nm}$ torsional torque. The torsion angle of the twisted trays was obtained from an angular measurement system of the stiffness tester to indicate the torsional stiffness of the trays.

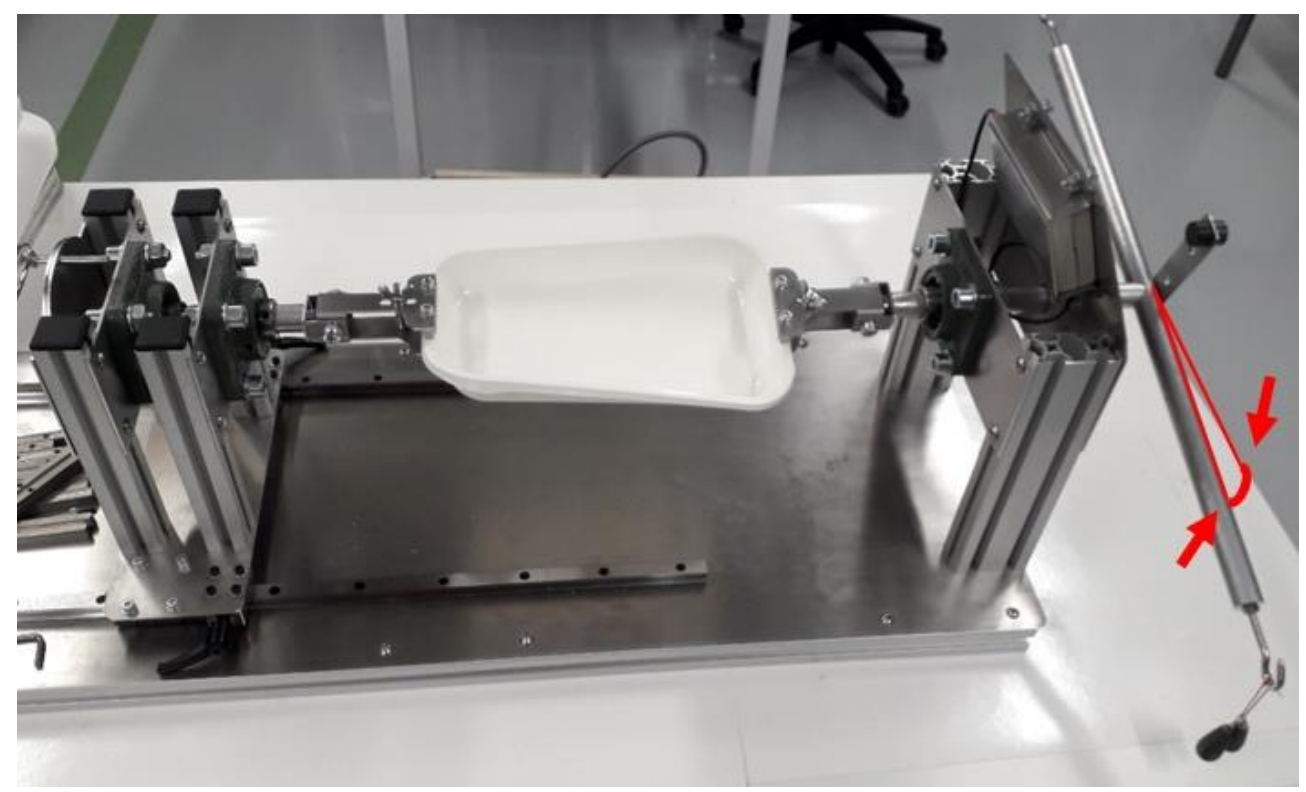

Fig. 5. Tray torsion test, torsion angle is highlighted with red arrows

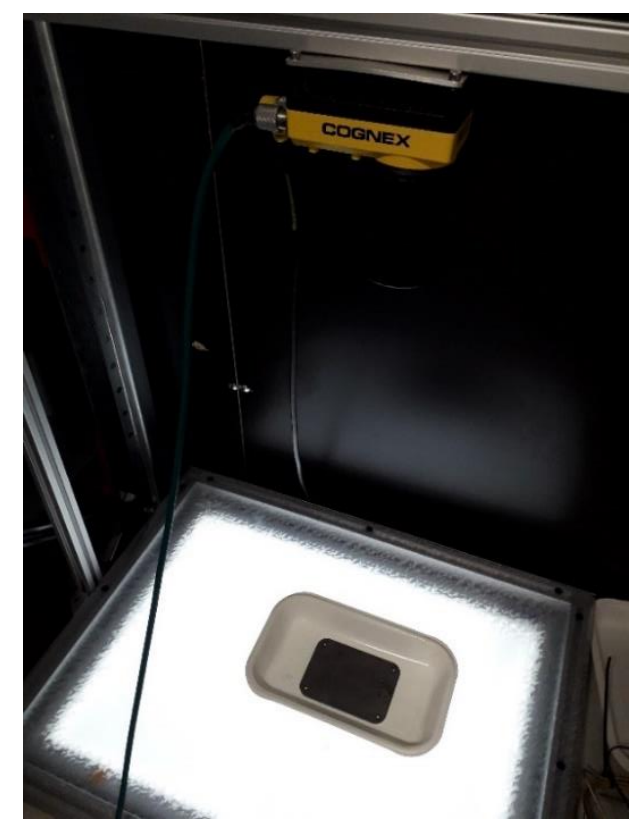

Fig. 6. Tray dimension measurement 
In the storing tests, the trays were stored inside a commercial refrigerator for $14 \mathrm{~d}$ at $4{ }^{\circ} \mathrm{C}$. The folded trays were heat-sealed and packed before they were stored to simulate the cold storing of food containers. The dimensions of the trays were measured before and after the storing using a quality monitoring system (part of the LUT packaging line). The monitoring system contained a Cognex IS5605-11 smart camera (Natick, MA, USA) and a backlit table to obtain the tray dimensions (Fig. 6). The moisture content of the trays was measured after the storing tests with the Adams Equipment PMB 53 moisture analyzer.

The folded trays were compared with the reference trays in the experiments. The reference trays were not folded after the press-forming process. The obtained compression, torsion, and storing test values were averaged from six samples per test. Two samples were observed in the optical analysis. All the tray samples were manufactured in one production run.

\section{RESULTS AND DISCUSSION}

The folding method created a permanent fold to the flange of the tray packages. The fold appeared in the form of a downward tilt of the tray flange (Fig. 7).

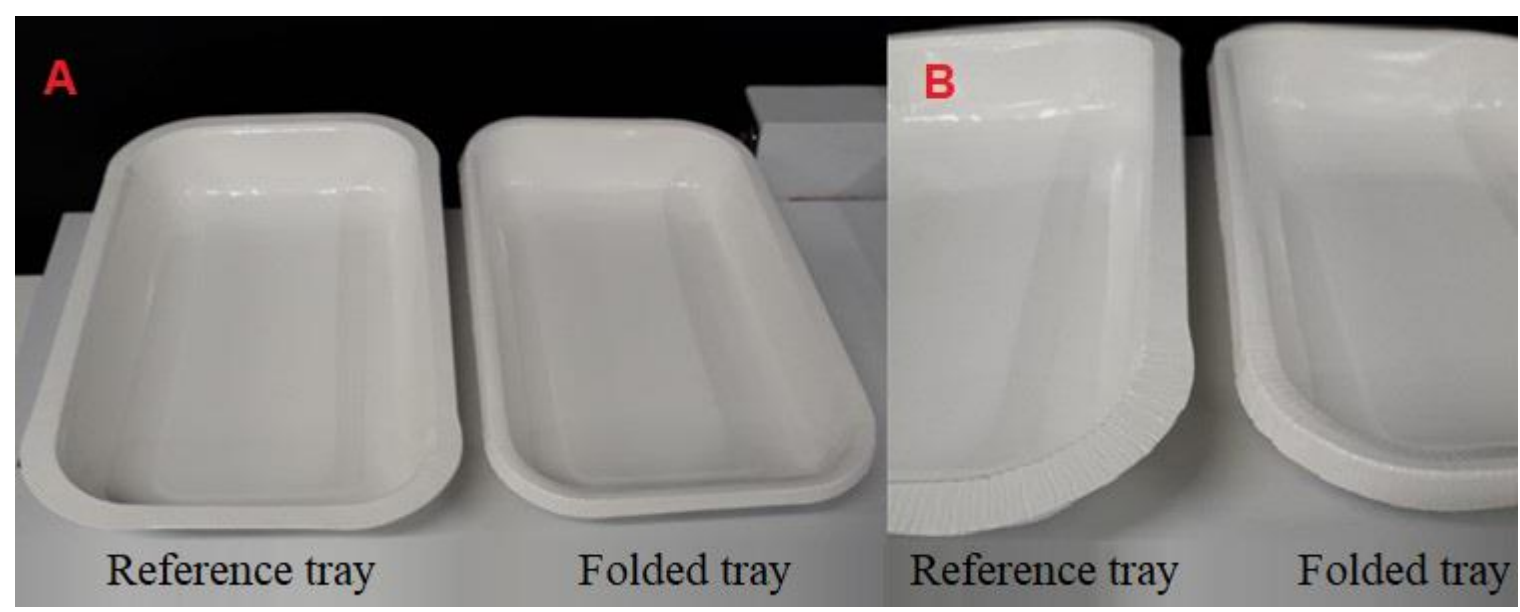

Fig. 7. (a) Tray and the b) tray flange before and after the folding

The folded trays remained heat-sealable despite the reduced contact area for the lidding of the trays. The lifting of the folded trays from the flange was hindered, yet the trays remained intact from their handling. The folding method had no effect on the tray geometry outside the flange region. The folded trays had comparable dimensions with all used folding temperatures, and the tray flange region of the folded trays showed only a minimal spring-back after the folding phase.

\section{Optical Analysis}

The surface topography of the material before the press-forming (Fig. 8) was graphed to benchmark the morphology of the PET coating for comparison with the pressformed and the folded samples. 


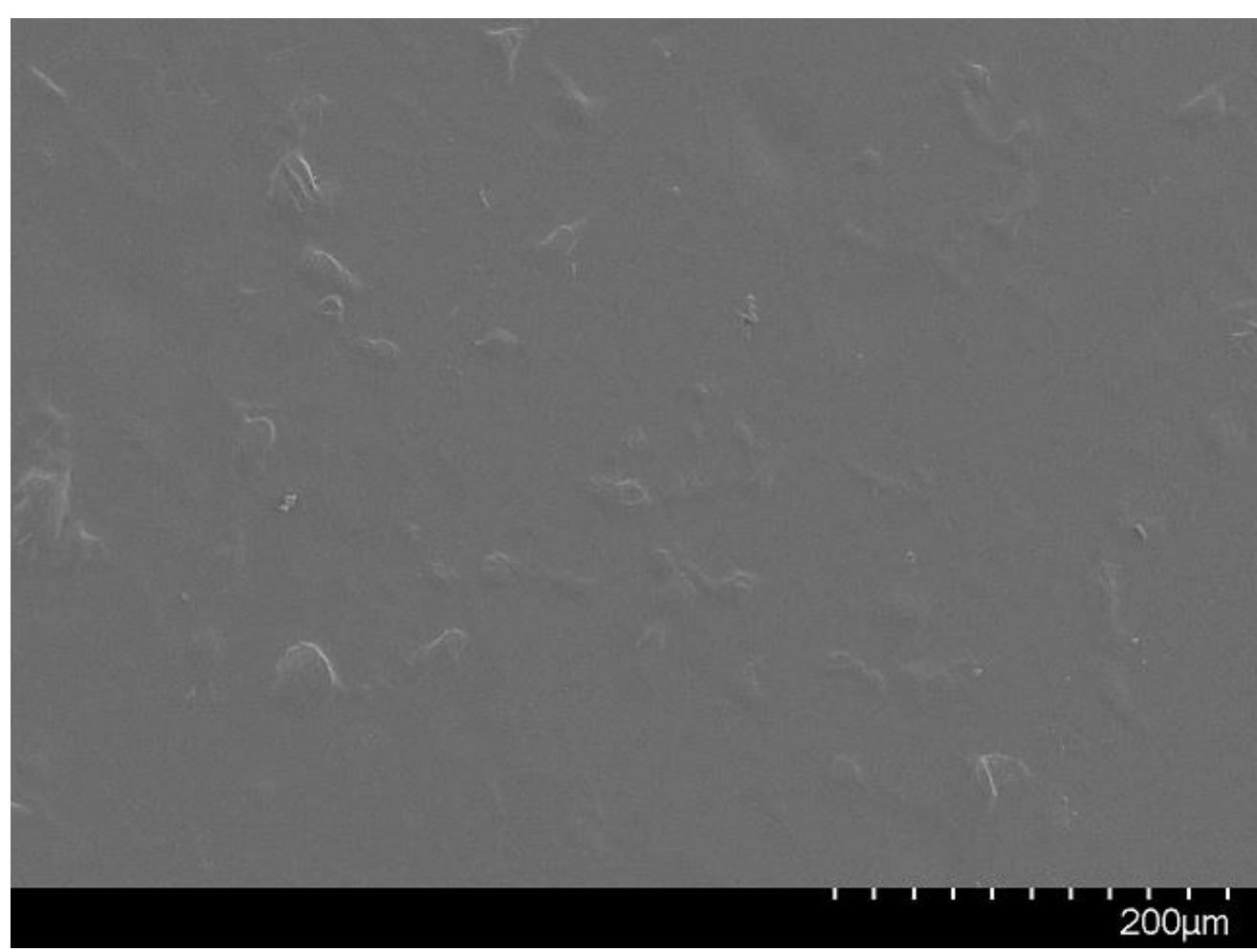

Fig. 8. Surface topography of the PET coating before the press-forming

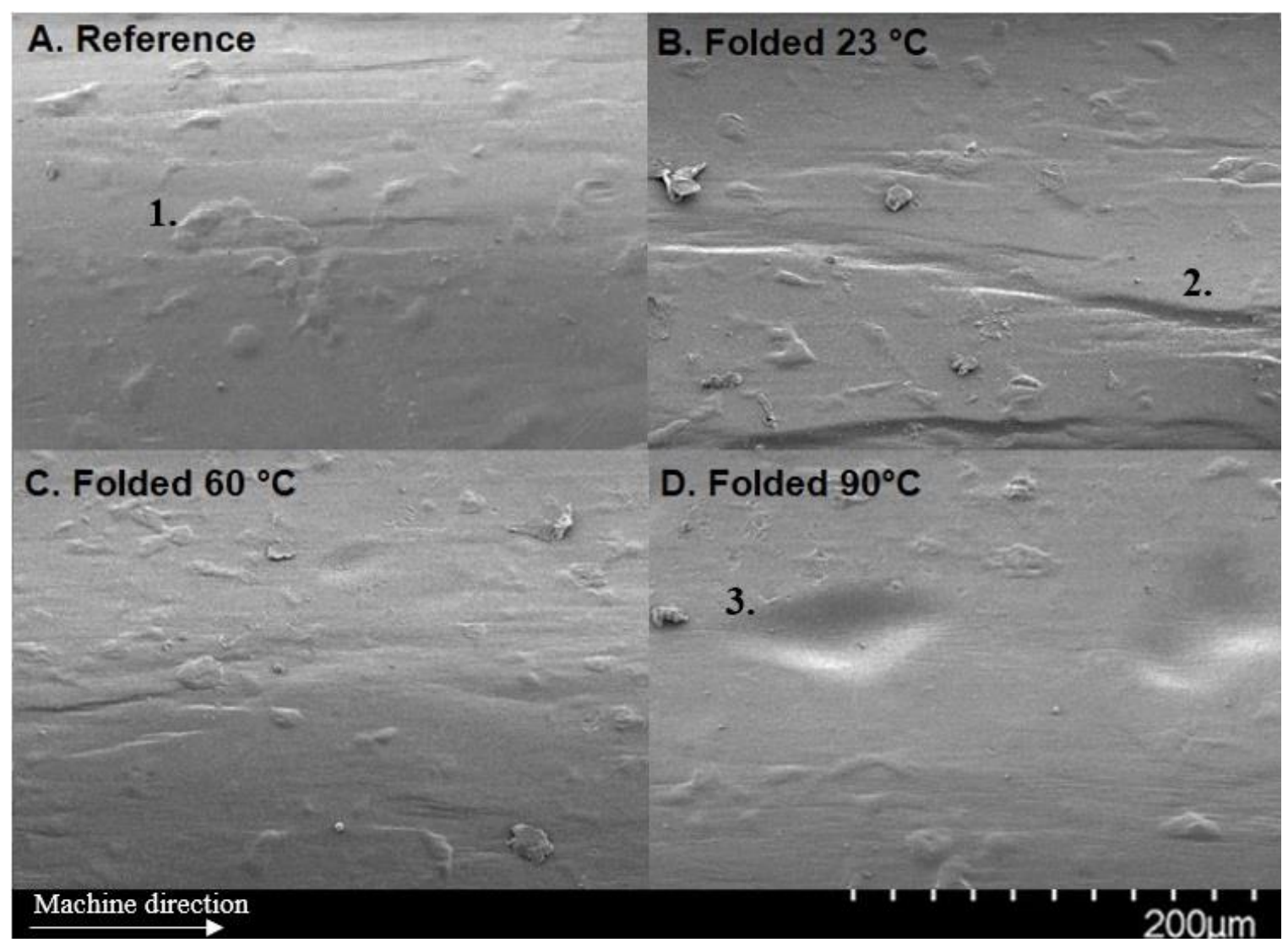

Fig. 9. Surface topography of the PET coating for the a) reference, b) folded at $23^{\circ} \mathrm{C}$, (c) folded at $60^{\circ} \mathrm{C}$, and (d) folded at $90^{\circ} \mathrm{C}$ samples 
The surface topography of the press-formed and the folded samples showed similar morphology changes in the obtained graphing results (Fig. 9). The obtained SEM images showed morphology changes in the form of crystallites (1), wrinkles (2), and lowered features (3).

Gould et al. (1998) proposed the PET structure to be formed by crystalline and amorphous zones based on the distribution and orientation of microfibrils. Gould et al. (1998) identified the amorphous zones by random orientations of the microfibrils and the crystalline zones by alignment of the microfibril chains along the fiber axis. The morphology changes were associated with the material heat exposure and elongation in the press-forming. The SEM images indicated similar crystalline and amorphous zones of the PET structure between the investigated samples. Accordingly, the folding phase only had a minor effect to the surface topography of the PET coating in comparison with the pressforming of the material.

The characteristics of PET were found to be different at the nanoscale and microscale by $\mathrm{Lu}$ et al. (2001), and atomic force microscopy (AFM) techniques were suggested for obtaining more detailed optical characteristics. The SEM images showed similar microscale characteristics of PET between the folded and the reference trays. In a previous work (Niini et al. 2021) the prolonged exposure of the PET coating to temperatures above $140{ }^{\circ} \mathrm{C}$ was connected to the noticeable crystalline growth on the surface topography. The folding of the trays at $90{ }^{\circ} \mathrm{C}$ or below showed no major effect on the crystalline growth on the PET coating as the optical quality of the folded trays and the reference trays was similar.

\section{Compression Tests}

The compression tests indicated increased compression strength with the folded trays, and the heat input in the folding phase showed a minor positive influence on the compression performance (Fig. 10). In comparison with the reference trays, the trays folded at room temperature had a $29 \%$ higher compression force. Using the same comparison, the compression force increased by $36 \%$ with the trays folded at $60{ }^{\circ} \mathrm{C}$ and by $43 \%$ with the trays folded at $90{ }^{\circ} \mathrm{C}$.

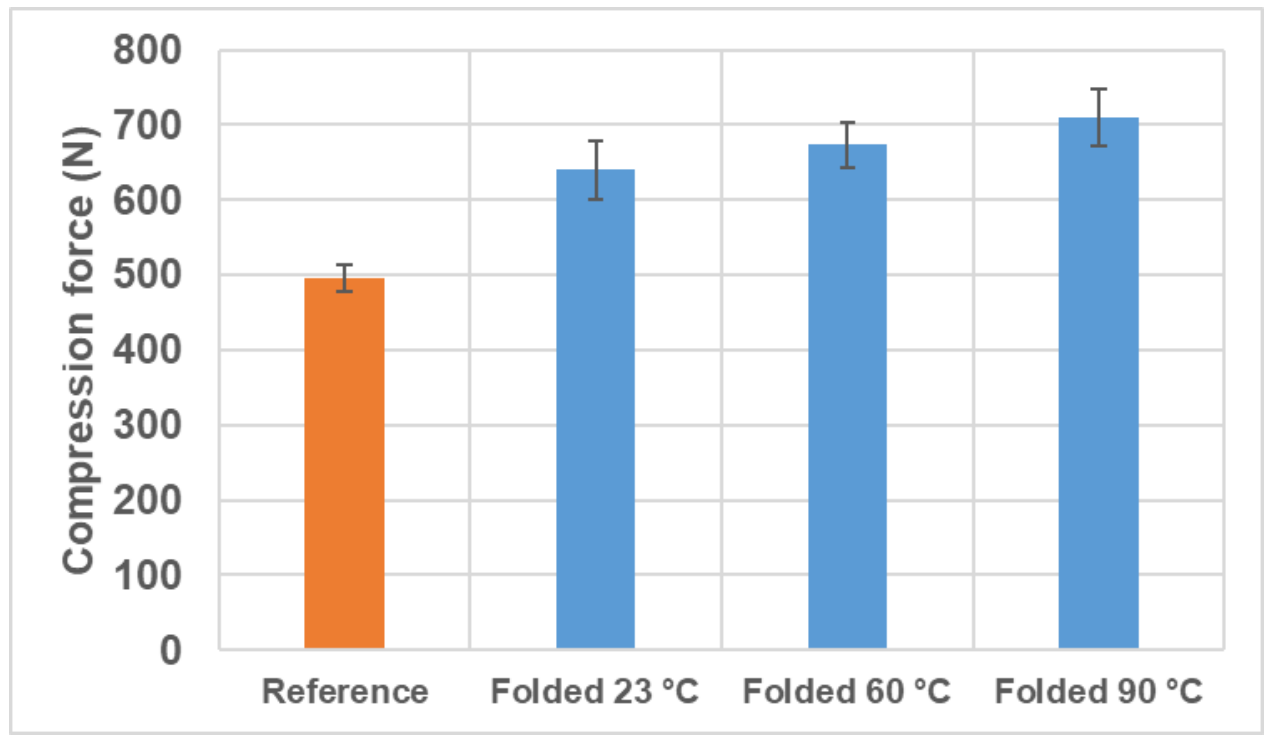

Fig. 10. Compression test results, standard deviation indicated with the error bars 
Beldie et al. (2001) found low initial stiffness of paperboard packages to be a consequence of low stiffness of the upper and lower package segments. The compression test results indicated improved initial stiffness of the folded trays, and the folding method was connected to the increased stiffness in the upper part of the tray package.

Dry paperboard has a higher tensile stiffness and strength compared to moist paperboard (Marin et al. 2020). An elevated folding temperature dried the flange region of the trays, and the drier upper part of the tray package positively influenced the compression performance. The results were in line with similar observations by Leminen et al. (2020) with respect to the positive effect of increased heat input to the compression strength of paperboard tray packages. In addition to the improved compression strength, the folding method can facilitate the stacking of the tray packages by preventing overlapping of the tray flanges between the stacked trays.

The processing conditions and the fiber-network structure greatly affect the mechanical response of paper-based materials, and bonding of the fibers influences the material deformation (Verma et al. 2013). The indicated compression strength of the folded trays was connected to the bonding of the fibers from the additional heat input and surface pressure induced to the tray flange region. The use of maximum folding parameters for the material was recommended to enhance the rigidification of the tray package.

\section{Torsion Tests}

Results from the torsion tests displayed a minor decrease in the torsion angle of the folded trays (Fig. 11). The torsion angle of the trays folded at $90{ }^{\circ} \mathrm{C}$ was $12 \%$ smaller in comparison to the torsion angle of the reference trays. The torsion angle of the trays folded at room temperature or at $60{ }^{\circ} \mathrm{C}$ was within the standard deviation of the torsion angle of the reference trays.

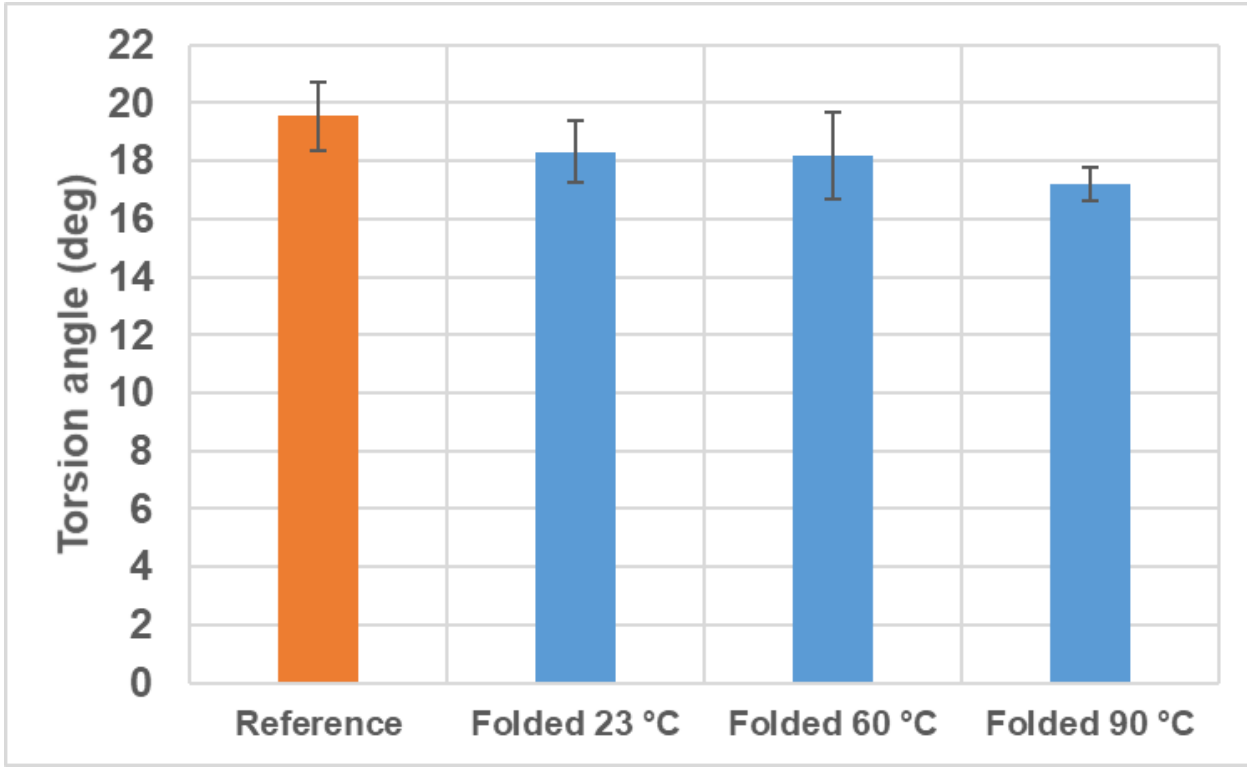

Fig. 11. Torsion test results

The tensile strength of tray corners is affected by the bonding of the polymer coating at the adjacent creases in the tray geometry (Leminen et al. 2020). The trays folded at $90{ }^{\circ} \mathrm{C}$ indicated improved strength and stiffness of the tray corners. The bonding of the 
polymer coating at the corner creases was assumed to improve from the additional heat input and surface pressure induced to the folded trays. The folding temperatures of 23 and $60{ }^{\circ} \mathrm{C}$ were below the glass transition temperature of $c a .70{ }^{\circ} \mathrm{C}$ for PET (Jog 1995), and their indicated effects to the bonding at the corner creases were smaller.

The effects from board asymmetry to the torsional stiffness of corrugated board were found insignificant by Hernández-Pérez et al. (2014), and consequently the effects from the material asymmetry to the obtained torsion test results were assumed minimal. The torsional stiffness of corrugated board samples is proportional to the shear stiffness in machine direction (MD) of the material, and the shear stiffness is used as a performance indicator with corrugated boxes (Chalmers 2006). Studying the shear stiffness of the folded trays are of interest for future research to further validate the effects of the developed folding method. Additionally, larger torsion loads can be used to characterize profile warping in the tray geometry.

\section{Storing Tests}

The measured moisture content of the trays was $7.5 \%$ after the storing tests, which was greater than the $6.3 \%$ recorded before the trays were stored. Consistent with the previous work (Niini et al. 2021), the material response to the moisture absorption was observed as a flange distortion on the longer sides of the tray (Figs. 12 and 13).

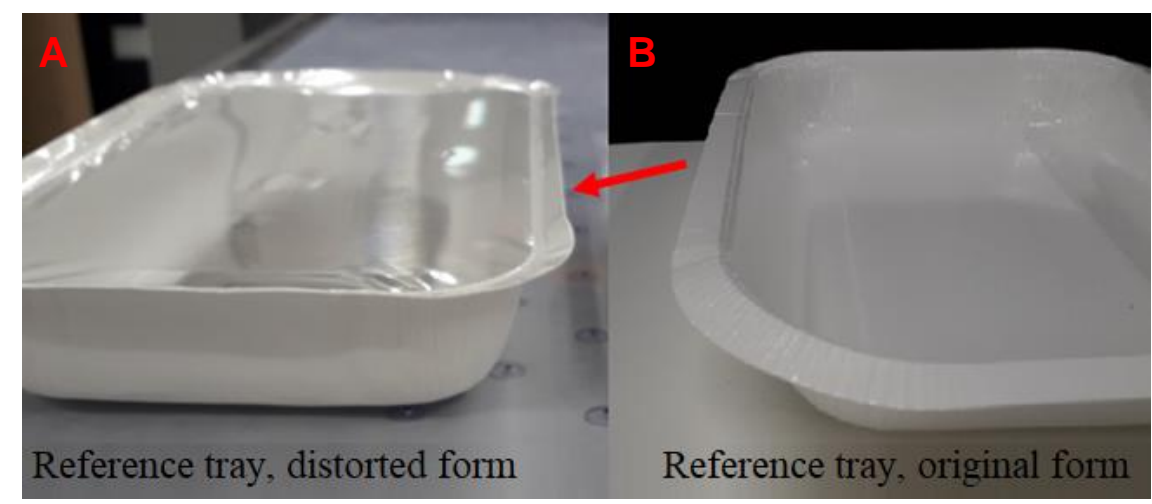

Fig. 12. Tray flange in the a) distorted form and the b) original form
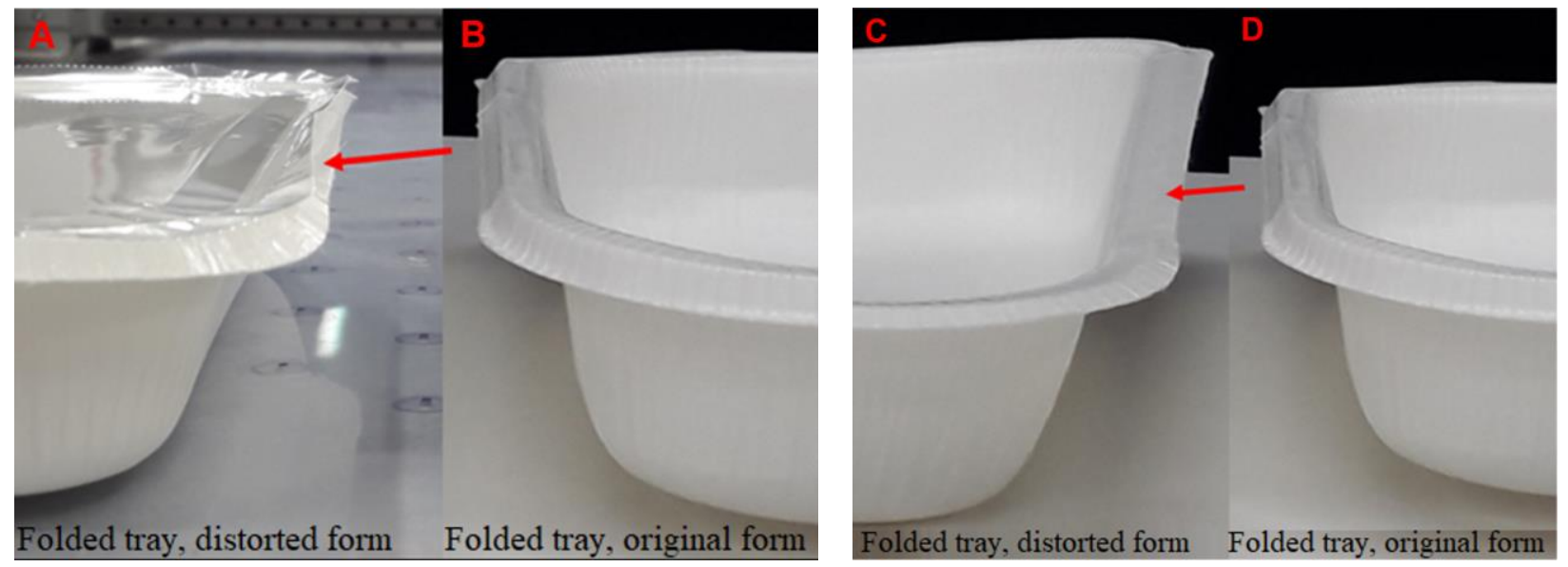

Fig. 13. Distortion of the tray flange with the lidding film in the a) distorted form and b) original form, and the distortion of the tray flange without the lidding film in the c) distorted form and d) original form 
The dimension measurements were focused on the tray width changes, as only minimal tray length changes were observed. The tray width was interpreted as the distance between the longer sides of the tray. After the storing tests, the tray flange tilted upwards with the reference trays and horizontally with the folded trays. As the dimensional measurements were recorded above the trays, the distortion of the tray flange affected the recorded width changes. Compared to the reference form of the tray flange, the upward tilt of the tray flange reduced the width of the reference trays, whereas the horizontal tilt of the tray flange increased the width of the folded trays (Fig. 14).

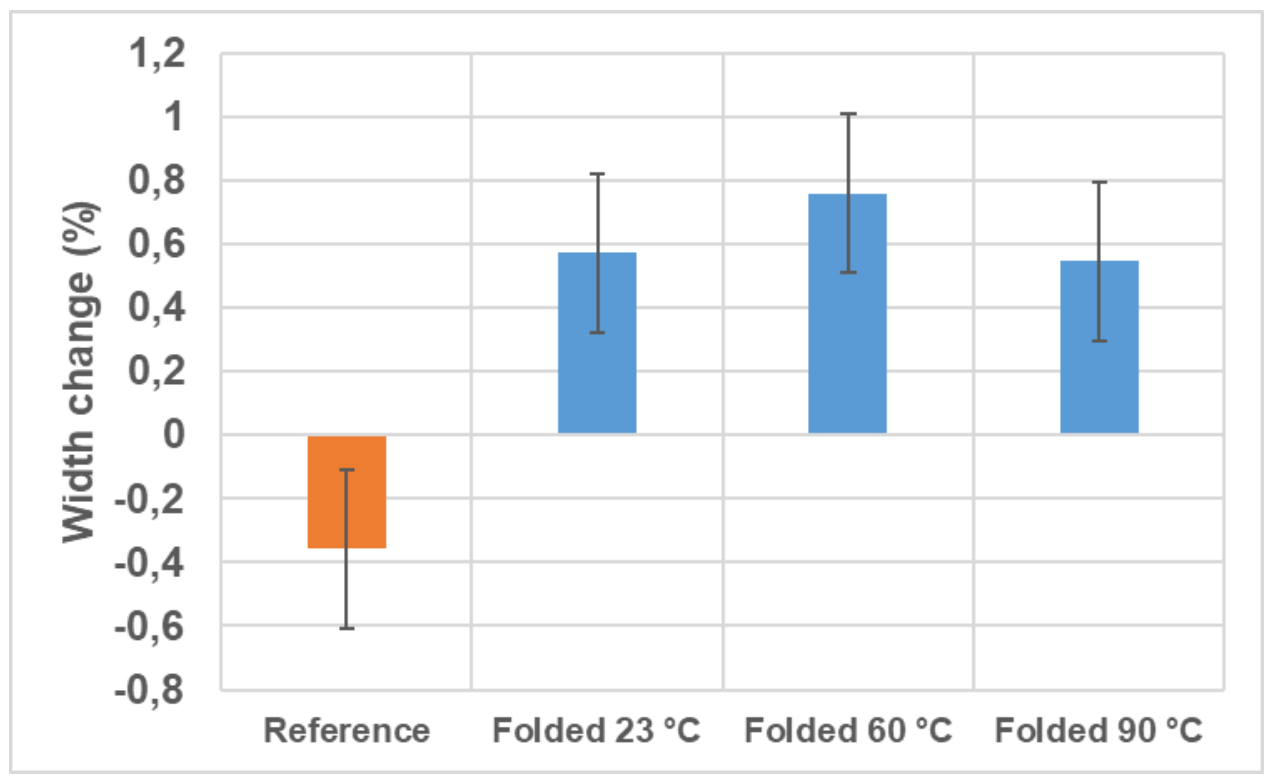

Fig. 14. Storing test results

Moisture absorption causes anisotropic hygroexpansion in paper-based materials, inducing curling in the structure (Viguié et al. 2011). The tray width changes were linked to the curling of the trays in the form of the tray flange distortion. The observed distortion depicted an upward spring-back of the tray flange. The tray walls and bottom appeared intact after the storing tests, and the sealing of the trays was associated with the preserved stability of the trays outside the flange region. The different orientation of the distorted tray flanges between the reference trays and the folded trays made the obtained dimension measurements difficult to compare directly, and accordingly the focus was concentrated to the material response.

The anisotropic hygroexpansion of paperboard affects the bonding of the fibers, as the unequal swelling of the fibers can cause shear stresses in the fiber network (Alfthan et al. 2002). The flange region of the folded trays was assumed to be drier due to the additional heat input from the folding phase. The dryer tray flange entailed unequal moisture uptake between the upper and lower part of the folded trays. The uneven moisture absorption was suggested as a possible aggravating effect to the dimensional stability of the folded trays.

Marin et al. (2020) showed a linear relationship between the moisture ratio and the normalized mechanical property. They found how doubling the moisture ratio of paperboard decreased the in-plane tensile strength and stiffness by $35 \%$ and $37 \%$, respectively. The distortion of the tray flange indicated major strength and stiffness 
degradation in the upper part of the tray packages. The folding method increased the stiffness and strength of the trays, yet it was found ineffective in reducing the distortion of the tray flange. As a result, the increased tray rigidity had only a minor effect on the dimensional stability.

\section{CONCLUSIONS}

1. The developed folding method was verified to increase the rigidity of paperboard tray packages in the compression and torsion tests. The method can be utilized to increase the load-bearing capacity of paperboard food containers.

2. The additional heat input and surface pressure induced to the material in the folding phase improved the compression strength and torsional stiffness of the trays. Elevated folding temperatures are recommended to obtain the increased tray rigidity, on the condition that the effects to the polymer coating of the tray package are considered.

3. The increased rigidity of the folded trays had an unclear effect in the storing tests. The dry upper part of the folded trays was suggested to aggravate the dimensional stability due to uneven moisture absorption in the material.

4. The operation of the developed folding device was validated and the integration of its mechanical structure and mode of operation into the design of press-forming tool set was evaluated to be possible. Adding the presented function to the process cycle can be recommended in certain packaging solutions, considering the improvements achieved with the studied tray packages.

\section{REFERENCES CITED}

Alfthan, J., Gudmundson, P., and Östlund, S. (2002). "A micromechanical model for mechanosorptive creep in paper," Journal of Pulp and Paper Science 28(3), 98-104.

Beldie, L., Sandberg, G., and Sandberg, L. (2001). "Paperboard packages exposed to static loads - Finite element modelling and experiments," Packaging Technology and Science 14(4), 171-178. DOI: 10.1002/pts.546

Berry, T. M., Fadiji, T. S., Defraeye, T., and Opara, U. L. (2017). "The role of horticultural carton vent hole design on cooling efficiency and compression strength: A multi-parameter approach," Postharvest Biology and Technology 124, 62-74. DOI: 10.1016/j.postharvbio.2016.10.005

Chalmers, I. R. (2006). "A new method for determining the shear stiffness of corrugated board," Appita Journal 59(5), 357-361.

Fadiji, T., Coetzee, C., Berry, T., and Opara, U. (2019). "Investigating the role of geometrical configurations of ventilated fresh produce packaging to improve the mechanical strength - Experimental and numerical approaches," Food Packaging and Shelf Life 20, 100321. DOI: 10.1016/j.fpsl.2019.100312

Gould, S. A. C., Schiraldi, D. A., and Occelli, M. L. (1998). "Analysis of poly(ethylene terephthalate) (PET) films by atomic force microscopy," Journal of Applied Polymer Science 65(7), 1237-1243. DOI: 10.1002/(SICI)10974628(19970815)65:7<1237::AID-APP1>3.0.CO;2-J 
Hauptmann, M., Wallmeier, M., Erhard, K., Zelm, R., and Majschak, J.-P. (2015). “The role of material composition, fiber properties and deformation mechanisms in the deep drawing of paperboard," Cellulose 22, 3377-3395. DOI: 10.1007/s10570-0150732-x

Hauptmann, M., Weyhe, J., and Majschak, J-P. (2016). "Optimisation of deep drawn paperboard structures by adaption of the blank holder force trajectory," Journal of Materials Processing Technology 232, 142-152. DOI: 10.1016/j.jmatprotec.2016.02.007

Hernández-Pérez, A., Hägglund, R., Carlsson, L., and Avilés, F. (2014). "Analysis of twist stiffness of single and double-wall corrugated boards," Composite Structures 110, 7-15. DOI: 10.1016/j.compstruct.2013.11.006

Hoffmann, J. (2000). "Compression and cushioning characteristics of moulded pulp packaging," Packaging Technology and Science 13(5), 211-220. DOI: 10.1002/10991522(200009)13:5<211::AID-PTS515>3.0.CO;2-0

Hofmann, A., Wallmeier, M., and Majschak, J.-P. (2019). "Characterization of the material elongation in the deep drawing of paperboard," Packaging Technology and Science 32(6), 287-296. DOI: 10.1002/pts.2436

Jog, J. P. (1995). "Crystallization of polyethyleneterephthalate," Journal of Macromolecular Science, Part C 35(3), 531-553. DOI: 10.1080/15321799508014598

Lamb, M. J., and Rouillard, V. (2017). "Static and dynamic strength of paperboard containers subjected to variations in climatic conditions," Packaging Technology and Science 30(3), 103-114. DOI: 10.1002/pts.2285

Leminen, V., Matthews, S., Pesonen, A., Tanninen, P., and Varis, J. (2018). "Combined effect of the blank holding force and forming force on the quality of press-formed paperboard trays," Procedia Manufacturing 17, 1120-1127. DOI: 10.1016/j.promfg.2018.10.026

Leminen, V., Tanninen, P., Matthews, S., and Niini, A. (2020). "The effect of heat input on the compression strength and durability of press-formed paperboard trays," Procedia Manufacturing 47, 6-10. DOI: 10.1016/j.promfg.2020.04.108

Lu, W., Debelak, K. A., Witt, A. R., Yang, C., Collins, W. E., and Lott, C. (2001). "Structural features of crystallized poly(ethylene terephthalate) polymers," Journal of Polymer Science Part B: Polymer Physics 40(3), 245-254. DOI: 10.1002/polb. 10086

Marin, G., Nygårds, M., and Östlund, S. (2020). "Stiffness and strength properties of five paperboards and their moisture dependency," Tappi Journal 19(2), 71-85. DOI: 10.32964/TJ19.2.71

Niini, A., Leminen, V., Tanninen, P., Varis, J., and Laukala, T. (2021). "The durability of press-formed paperboard trays - Effects of sealing and drying," BioResources 16(1), 236-248. DOI: 10.15376/biores.16.1.236-248

SFS-EN 631-1 (2013). "Materials and articles in contact with foodstuffs. Catering containers. Part 1: Dimensions of containers," Finnish Standards Association, Helsinki, Finland.

Stein, P., Franke, W., von Elling, M., and Groche, P. (2019). "Forming behavior of paperboard in single point forming," BioResources 14(1), 1731-1764. DOI: 10.15376/biores.14.1.1731-1764

Sørensen, G., and Hoffmann, J. (2003). "Moisture sorption in moulded fibre trays and effect on static compression strength," Packaging Technology and Science 16(4), 159-169. DOI: $10.1002 /$ pts.622 
Sørensen, G., and Hoffmann, J. (2004). "Moisture-induced effects on stacking strength of moulded-fibre packaging in varying environmental conditions," Packaging Technology and Science 17(5), 257-265. DOI: 10.1002/pts.661

Tanninen, P., Leminen, V., Matthews, S., Kainusalmi, M., and Varis, J. (2018). "Process cycle optimization in press forming of paperboard," Packaging Technology and Science 31(5), 369-376. DOI: 10.1002/pts.2331

Verma, P., Shofner, M. L., and Griffin, A. C. (2013). "Deconstructing the auxetic behavior of paper," Physics Status Solidi b 251(2), 289-296. DOI: 10.1002/pssb.201384243

Viguié, J., Dumont, P., Mauret, É., Roscoat, S., Vacher, P., Desloges, I., and Bloch, J-F. (2011). "Analysis of the hygroexpansion of a lignocellulosic fibrous material by digital correlation of images obtained by X-ray synchroton microtomography: Application to a folding box board," Journal of Materials Science 46, 4756-4769. DOI: $10.1007 / \mathrm{s} 10853-011-5386-\mathrm{y}$

Wang, Z.-W., and Sun, Y.-C. (2018). "Experimental investigation on bending fatigue failure of corrugated paperboard," Packaging Technology and Science 31(9), 601609. DOI: $10.1002 /$ pts. 2390

Article submitted: October 22, 2021; Peer review completed: December 19, 2021;

Revised version received and accepted: January 3, 2022; Published: January 10, 2022.

DOI: 10.15376/biores.17.1.1427-1441 